\title{
Immunoexpression of inhibitors of apoptosis proteins and their antagonist SMAC/DIABLO in colorectal carcinoma: Correlation with apoptotic index, cellular proliferation and prognosis
}

\author{
FLÁVIO DE OLIVEIRA LIMA ${ }^{1}$, HENRIQUE DE OLIVEIRA COSTA ${ }^{1}$, LUIS FERNANDO MESIAS BARREZUETA ${ }^{1}$, \\ CELINA TIZUKO FUJIYAMA OSHIMA ${ }^{1}$, JOSÉ ANTONIO SILVA Jr ${ }^{2}$, THIAGO SIMÃO GOMES ${ }^{1}$, \\ NATHANAEL PINHEIRO Jr ${ }^{1}$, RICARDO ARTIGIANI NETO ${ }^{1}$ and MARCELLO FRANCO ${ }^{1}$ \\ ${ }^{1}$ Department of Pathology, Federal University of São Paulo (EPM-UNIFESP), Rua Botucatu 740, São Paulo, \\ Vila Clementino, CEP 04023-062; ${ }^{2}$ Uninove (Universidade Nove de Julho, São Paulo), Brazil
}

Received February 2, 2009; Accepted April 13, 2009

DOI: 10.3892/or_00000437

\begin{abstract}
The inhibitors of apoptosis proteins (IAPs) act by directly blocking cleaved caspase-3 (XIAP) or the protein SMAC/DIABLO, an antagonist. The inhibition of XIAP activity or the increase of SMAC activity might improve the therapeutic response of the patients. This work evaluated the immunoexpression of IAPs and SMAC in colorectal carcinoma and their correlation with apoptotic index (AI), cellular proliferation, p53 protein immunoexpression and patient survival rate. TMA paraffin blocks were made with colorectal cancer tissue and adjacent non-tumorous mucosa of 130 patients, not submitted to radio or chemotherapy. Sections of $4 \mu \mathrm{m}$ were processed by immunohistochemistry for survivin, XIAP, cIAP-1, cIAP-2 and SMAC, and the immunoexpression scores were obtained. They were correlated between each other and with the AI obtained by anticleaved caspase-3 and M30 (cleaved cytokeratin-18) antibodies, the cellular proliferation index, $\mathrm{p} 53$ protein immunoexpression and patient survival data. Direct correlation occurred between the four IAPs studied in tumor and nontumorous mucosa tissues. SMAC, survivin, cIAP-1 and cIAP-2 were positively correlated with tumoral tissue AI. Cellular proliferation and p53 immunoexpression was positively correlated with XIAP, SMAC and cIAP-1 scores. Low cIAP-1 immunoexpression showed a tendency for correlation with shorter patient survival. Equilibrium between the activities of IAPs and SMAC was demonstrated by the direct correlation between their immunoexpression. Correlation between SMAC and AI confirmed the pro-apoptotic activity of this protein. XIAP showed no inverse correlation with AI. XIAP, SMAC and cIAP-1 play a role in colorectal tumorigenesis, as
\end{abstract}

Correspondence to: Dr Flávio de Oliveira Lima, Department of Pathology, Federal University of São Paulo (EPM-UNIFESP), Rua Botucatu 740, São Paulo, Vila Clementino, CEP 04023-062, Brazil E-mail: flavioolima@uol.com.br

Key words: colorectal carcinoma, immunohistochemistry, IAPs, SMAC, apoptosis, prognosis demonstrated by their direct correlation with cellular proliferation and p53 protein. The tendency for correlation between low cIAP-1 immunoexpression and survival might indicate a role for this protein as a prognostic marker in colorectal cancer.

\section{Introduction}

Colorectal carcinoma is a frequent cause of morbidity and mortality in Western populations, showing high frequency in Brazil, particularly in southern and south eastern states (Health Ministry; Ministério da Saúde, http://www.datasus. gov.br). Estimates for 2008 for the south eastern region report an approximate incidence of 12.05-26.35 men and 13.42-28.22 women per 100000 inhabitants (National Cancer Institute; Instituto Nacional do Câncer, http://www.inca. gov.br/).

Colorectal carcinogenesis occurs in multiple cumulative stages, including mutational activation of oncogenes associated with the inactivation of tumor suppressor genes $(1,2)$. Given this context, several metabolic pathways of cellular proliferation, DNA repair and apoptosis have been studied (3-8).

Apoptosis (programmed cell death) is an efficient physiological mechanism for cell suicide that is important for growth and cell differentiation processes in multicellular animals, controlling the number of cells and organ size (9). It is activated by two pathways: the cell death receptor or extrinsic pathway and the mitochondrial or intrinsic pathway. Both pathways promote the activation of the caspase cascade, a family of cysteine proteases that constitute the central regulatory mechanism of death by apoptosis. The morphological alterations observed in apoptosis are induced by the action of the caspases, especially by caspase-3, the principal trigger of the apoptotic process (10). One of the striking characteristics of the great majority of cancers is their progressive resistance to apoptosis.

The IAPs are a family of molecular inhibitors of apoptosis, encoded by genes present in mammals and phylogenetically conserved. They are also found in Drosophila and in certain viruses. The apoptotic process evolved with a series of amplification mechanisms that once triggered rapidly reaches irreversibility. Thus, the existence of inhibitory molecules is 
explained by the necessity of the cells to protect themselves against environmental triggers that might function as spurious signals and lead to non-physiological death by apoptosis. The IAPs exert an antiapoptotic role by inhibiting the activity of effector caspases-3 and -7 , and the initiator caspase-9, and are the only known endogenous proteins that present such activity. It has been postulated that in viable cells the basal activity of caspases is inhibited by IAPs, such that the presence of these proteins places limits on caspase activation (10). The principal molecular characteristic of IAPs is the presence of one or more baculovirus IAP repeat (BIR) domains. Isolated BIR domains inhibit caspase activation in vitro and are the principal functional units of IAPs (11). Seven different members of the IAP family have been described: NAIP, XIAP, c-IAP-1, c-IAP-2, Livin (or ML-IAP), TsIAP (ILP-2) and survivin.

XIAP is the most potent caspase inhibitor and the only IAP that inhibits mature activated caspases at physiological concentrations, presenting as the most potent caspase inhibitor in vitro. It inhibits caspase- 3 and -7 at nanomolecular (physiological) concentrations by inserting a residue of aspartic acid into the active catalytic site of the caspase, corresponding to the inverse spatial orientation adopted by activator substrates when these bind to same catalytic sites.

Caspase- 9 inhibition occurs by a distinct mechanism. At physiological concentrations the BIR-3 domain binds to the processed amino terminal of monomeric caspase- 9 , impeding its dimerization and consequent activation $(10,12-14)$. Caspase- 9 expression is activated via the Che- 1 protein in response to DNA damage (15). Its deficiency was identified as the cause of the lymphoproliferative syndrome linked to the $\mathrm{X}$ chromosome (16). XIAP has been investigated as a therapeutic target, aimed at improving sensitization to apoptosis by chemotherapy (17-20).

Survivin is amply expressed in fetal and embryonic cells and it was initially believed that was silenced in normal nonneoplastic adult cells. However, it has been observed in nonneoplastic colon mucosa by RT-PCR and immunohistochemistry $(21,22)$. It fulfills a function in the cell cycle, as the only IAP associated with chromatinic structures, and monitors the success of chromosome segregation and replication, suppressing the nuclear caspases. At 16.5 kDa, it is the smallest mammalian IAP. It presents only one BIR domain and three transcripts: the wild form and two isoforms, survivin $\Delta \mathrm{Ex} 3$ and survivin $2 \mathrm{~b}$. Its predominant cytoplasmatic location is determined by CRM-1-dependent export from the nucleus. A lysine-rich sequence is required at its carboxylterminal for this exportation, a sequence that is absent in the nuclear isoform $\Delta \mathrm{Ex} 3$ (23). Survivin is overexpressed in a series of transformed cell lines and in lung, intestine, pancreas, prostrate and breast cancer cells and non-Hodgkin lymphoma, and is associated with recurrence risk factors and poor prognosis. It is significantly correlated with p53 protein mutation in breast carcinomas (11-13,24-26).

Despite its immunolocalization in gels containing caspases-3 and -9 , it does not physically bind to caspases or directly inactivate them. The antiapoptotic activity is derived by its binding to the IAPs inhibitors SMAC-DIABLO and OmiHtrA2, leading to ubiquitylation, degradation and liberation of XIAP to bind and inhibit caspases (26-28).
cIAP-1 and cIAP-2 (cellular IAP) form part of the proteic complex of the intracytoplasmatic domain of the transmembrane protein TNF- $\alpha-2$. cIAP-1 forms part of the proteic complex of the cytoplasmic domain TRAF-2 and TRADD of the TNFR-1, as such, it is a potent apoptosis inhibitor mediated by TNF- $\alpha$ (11). Similar to XIAP, cIAP-1 and cIAP-2 possess three BIR domains and one RING domain. In addition, they also possess a CARD domain (Caspase Recruitment Domains) between BIR-3 and one RING. These domains are not required for antiapoptotic action and are most likely involved in mediating interactions with other apoptosis regulatory proteins and the proteosome system $(13,14)$. Although physically capable of binding with caspases, it does not occur at physiological concentrations. The three indirect mechanisms of their apoptosis inhibition activity are: i) by binding to IAP antagonists like SMAC/DIABLO, thus reducing their concentration and leaving more XIAP molecules free to inhibit caspases; ii) by influencing NF-кB and MAP-kinase signaling; or iii) by marking caspases for ubiquitylation and proteosome degradation (12). cIAP-2 expression is stimulated by NF- $\mathrm{B}$ and COX-2, such that an increase in these proteins promotes apoptosis resistance due to cIAP-2 increase. Studies involving the blockage of NF- $\mathrm{KB}$ and COX-2 by RNA interference show that diminished levels of cIAP-2 and XIAP are related to diminished apoptosis resistance (29-31).

SMAC (Secondary Mitochondrial Activation of Caspases) is a mitochondrial protein liberated in cytosol similar to cytochrome $\mathrm{C}$ after apoptotic stress. SMAC is located in the intermembrane mitochondrial space as a mitochondrial precursor protein and is activated by the removal of the Nterminal sequence. It binds to all IAPs to which it was submitted during inhibition studies. SMAC binds specifically to the BIR-2 and BIR-3 domains in XIAP through an IAP domain motif RHG (REAPER/HID/GRIM) and by IBMs (IAP Binding Motifs) at the same biding site as caspase-9, thus impeding their inhibition.

The antiapoptotic action of certain IAPs, such as survivin and livin, occur by molecular sequestration of SMAC/ DIABLO, liberating XIAP molecules for caspase inhibition $(28,32,33)$. Mathematical models have been proposed to describe the relation between the number of survivin, XIAP and SMAC/DIABLO molecules. Loss of the molecular homeostasis leads cells toward apoptosis or permits the survival of cells presenting genetic alterations $(27,34,35)$.

The strategy of research involving therapeutic agents that promote increased sensitivity to apoptosis in tumor cells is aimed at inhibiting IAPs, whether by molecular inhibitors or recombinant proteins $(36,37)$.

The potential therapeutic use of IAP inhibitors attempts to increase sensitivity to apoptosis induced by chemotherapy and radiotherapy of tumor cells. The same IAPs also show potential therapeutic use in preventing the progression of neurodegenerative diseases by impeding the neuronal apoptosis, involved in the progression of these diseases.

Our goal is to evaluate the immunoexpression of survivin, XIAP, cIAP-1, cIAP-2 and SMAC/DIABLO in colorectal cancer tissue of patients who were not submitted to radio or chemotherapy, and correlate the immunoexpression of these proteins with the Apoptotic Index, cellular proliferation, p53 protein immunoexpression and patient survival rate. 


\section{Materials and methods}

The tissue samples studied were embedded in paraffin blocks belonging to 130 colorectal cancer patients operated on at São Paulo Hospital of the Paulista School of Medicine of São Paulo Federal University (Escola Paulista de Medicina, Universidade Federal de São Paulo; EPM/UNIFESP) between 2002 and 2005, who were not submitted to radio or chemotherapy before surgery. All patients had post-operatory adjuvant treatment.

The age of patients ranged from 20 to 88 years, with the majority of patients 56-70 years. We had equal gender distribution in the sample ( 65 man, and 65 women). Forty percent of the tumors were well differentiated, $54 \%$ were moderately, and $6 \%$ were poorly differentiated. Tubular carcinoma was the most common histological type, with 104 patients, flowed by mucinous (15) and medullar (10). One patient had a adenoescamous carcinoma. Most of patients were in Dukes' stages C and B. Sixty patients had no metastases, and 70 had metastases only in regional nodes. Fifty-seven patients were alive at the time this study was finished, and 34 died of the tumor.

The colorectal cancer tissue samples, obtained from surgical specimens, were fixed in $10 \%$ formalin and routinely processed by embedding in paraffin for histological analysis. Histological sections ( $4 \mu \mathrm{m})$ were cut from each block and stained by hematoxylin-eosin. The microslides were read for diagnostic confirmation and re-evaluation of the histopathological findings, including the selection of sites for the removal of cylindrical cores used in Tissue Microarray (TMA) block construction. The histological grade was assessed according the WHO classification of tumors (38).

TMA blocks were constructed using Beecher ${ }^{\mathrm{TM}}$ equipment (Beecher Instruments, Silver Spring, MD, USA) according to the manufacturer's instructions, in the following stages: i) the selected area in the respective paraffin block was marked; ii) a cylindrical core was created in the receptor block using the apparatus; iii) a 1-mm cylinder of tissue was extracted from the area of interest; iv) the cylindrical tissues obtained from the donating block was transferred to the core in the receptor block; v) new core positions were created in the receptor block, separated by fractions of millimetre such that a collection of tissue samples was created following the matrix arrangement; vi) the quality of the block was assessed before storing. Two samples of each tumor were used to construct the TMA paraffin block, in order to lessen sample losses. To guarantee adhesion of the TMA block slices on the slides, an adhesive tape system (Instrumedics Inc., Hackensak, NJ, USA) was used.

The streptavidin-biotin method was used for the immunohistochemistry. The primary antibodies used were monoclonal survivin (D-8) antibody (Santa Cruz Biotechnology, CA, USA) diluted 1:300, monoclonal anti-XIAP (AB-2) antibody (Calbiochem, Germany) diluted 1:1000, polyclonal anti-cIAP-1 (H83) antibody (Santa Cruz) diluted 1:300, polyclonal anti-cIAP-2 antibody (Santa Cruz) diluted 1:100, monoclonal anti-SMAC/DIABLO (10G7) antibody (Calbiochem) diluted 1:400, monoclonal P53 (Bp53-12, sc263) antibody (Santa Cruz) diluted 1:1500, monoclonal antiKi-67 (clone MIB-1, M7240) antibody (DakoCytomation, CA, USA) diluted 1:100, polyclonal anti-cleaved-caspase-3
Table I. Cut-offs for the distinction between groups with no/ weak and strong expression of the markers and results of the log-rank test of the survival curves built with these thresholds.

\begin{tabular}{lccc}
\hline Marker & Cut-off & P-value & $\mathrm{N}$ \\
\hline cIAP-1 & $<6$ & 0.3694 & 110 \\
SMAC & $<6$ & 0.4041 & 110 \\
Survivin & $<6$ & 0.4458 & 111 \\
Ki-67 & $<4$ & 0.6082 & 111 \\
p53 & $<4$ & 0.6114 & 110 \\
XIAP & $<6$ & 0.6884 & 111 \\
M30 & $<3$ & 0.7012 & 110 \\
cIAP-2 & $<6$ & 0.8067 & 111 \\
Caspase-3 & $<6$ & 0.9333 & 111 \\
\hline
\end{tabular}

(AP1027) antibody (Calbiochem) diluted 1:1000, and anticleaved cytokeratin 18 (M30 CytoDEATH) antibody (Roche, NJ, USA) diluted 1:500. The amplification system used was the LSAB+ System HRP kit (Dako, CA, USA). Colors were developed with 3,3'diaminobenzidine (DAB) (Sigma Chemicals Co., St. Louis, MO, USA), which was counterstained with Harris hematoxylin.

The positivity pattern for the anti-protein primary antibodies of the IAP family was the appearance of brownish staining in the nuclear region or cell cytoplasm. Positive control slides were used containing histological slides previously proven as positive for the markers studied. The slides stained omitting the primary antibody were used as negative controls.

The criterion used to evaluate the immunoexpression of XIAP, survivin, cIAP-1, cIAP-2, SMAC/DIABLO, p53 and $\mathrm{Ki}-67$ was the stain intensity, scored from 0 to 3 , with 0 considered negative, 1 as weak, 2 as intermediary and 3 as strong. The number of positive cells was evaluated on a scale of $0-3$; where 0 corresponded to $0-10 \%$ of cells, 1 corresponded to $11-25 \%, 2$ corresponded to $26-50 \%$ and 3 corresponded to $>51 \%$ of cells. The slides were read independently by three experienced pathologists who had no information on patient conditions. A score was obtained for each reaction by multiplying the intensity of the reaction by the percentage of positive cells. Discrepancies were solved with consensus after multi-head microscope meeting. The immunoexpression of the markers was evaluated, both in tumor tissues and in the mucosa obtained from the surgical margins or adjacent to the tumor (39). The immunoexpression of markers presenting different histological types, such as tubular, mucinous and medullary, where evaluated separately. Evaluation of the AI was based on the immunoexpression of cleaved caspase-3 and M30 (cleaved cytokeritin-18). A ImageLab ${ }^{\mathrm{TM}}$ software and image capture system and an Olympus ${ }^{\mathrm{TM}}$ trinocular microscope, model BX-40 was used, for cell counts. Positive cells were counted in 200 cells in fields presenting more intense and numerous staining ('hot-spots') in adjacent areas (40).

The patients were grouped by low/negative expression and intermediate/strong expression of the markers studied. The cut-offs for these groups were obtained by plotting the data in histograms and represented the value in the end of the first peak observed (Table I). Patient survival in the two groups 
Table II. Correlation of the immunoexpression between the markers in the tumor tissue.

\begin{tabular}{|c|c|c|c|c|}
\hline Marker 1 & Marker 2 & P-value & $\mathrm{r}$ & $95 \%$ CI \\
\hline cIAP-2 & SMAC & $<0.0001$ & 0.34 & 0.1726-0.4884 \\
\hline cIAP-1 & Caspase-3 & $<0.0001$ & 0.3643 & 0.1979-0.5102 \\
\hline Survivin & XIAP & $<0.0001$ & 0.3764 & $0.2134-0.5190$ \\
\hline SMAC & Survivin & $<0.0001$ & 0.3880 & $0.2256-0.5293$ \\
\hline cIAP-2 & XIAP & $<0.0001$ & 0.3999 & 0.2397-0.5389 \\
\hline cIAP-1 & Ki-67 & $<0.0001$ & 0.4241 & $0.2649-0.5607$ \\
\hline SMAC & Ki-67 & $<0.0001$ & 0.4421 & $0.2867-0.5748$ \\
\hline cIAP-1 & Survivin & $<0.0001$ & 0,4590 & 0.3048-0.5898 \\
\hline SMAC & Caspase-3 & $<0.0001$ & 0.4768 & $0.3266-0.6035$ \\
\hline Caspase-3 & M30 & $<0.0001$ & 0.5164 & $0.3728-0.6359$ \\
\hline cIAP-1 & cIAP-2 & $<0.0001$ & 0.5370 & 0.3958-0.6534 \\
\hline cIAP-1 & SMAC & $<0.0001$ & 0.6018 & $0.4730-0.7054$ \\
\hline cIAP-2 & Survivin & $<0.0001$ & 0.7317 & $0.6371-0.8046$ \\
\hline Survivin & Caspase-3 & 0.0001 & 0.3157 & $0.1467-0.4668$ \\
\hline cIAP-2 & Caspase-3 & 0.0002 & 0.3068 & 0.1370-0.4591 \\
\hline SMAC & M30 & 0.0002 & 0.3069 & $0.1357-0.4603$ \\
\hline cIAP-1 & p53 & 0.0002 & 0.3127 & 0.1413-0.4659 \\
\hline SMAC & p53 & 0.0003 & 0.3001 & 0.1291-0.4538 \\
\hline cIAP-2 & p53 & 0.0005 & 0.287 & $0.1156-0.4417$ \\
\hline M30 & KI-67 & 0.0007 & 0.2790 & $0.1064-0.4353$ \\
\hline Survivin & p53 & 0.0013 & 0.2630 & 0.08994-0.4206 \\
\hline cIAP-2 & M30 & 0.0015 & 0.2600 & 0.08608-0.4185 \\
\hline Caspase-3 & Ki-67 & 0.0028 & 0.2421 & 0.06778-0.4021 \\
\hline cIAP-1 & XIAP & 0.008 & 0.2133 & 0.03532-0.3781 \\
\hline cIAP-1 & M30 & 0.0092 & 0.2099 & 0.03104-0.3757 \\
\hline Survivin & M30 & 0.0134 & 0.1949 & 0.01759-0.3603 \\
\hline SMAC & XIAP & 0.0142 & 0.1930 & $0.01560-0.3586$ \\
\hline Ki-67 & p53 & 0.0157 & 0.1888 & 0.01204-0.3542 \\
\hline XIAP & Ki-67 & 0.0211 & 0.1784 & $0.001269-0.3448$ \\
\hline cIAP-2 & Ki-67 & 0.0275 & 0.1687 & $-0.008809-0.3358$ \\
\hline XIAP & M30 & 0.0626 & 0.1357 & $-0.04327-0.3062$ \\
\hline Survivin & Ki-67 & 0.065 & 0.1335 & $-0.04479-0.3035$ \\
\hline Caspase-3 & p53 & 0.0723 & 0.1286 & $-0.04971-0.2990$ \\
\hline M30 & p53 & 0.0993 & 0.1139 & $-0.06530-0.2860$ \\
\hline XIAP & Caspase-3 & 0.1324 & 0.0985 & $-0.08011-0.2710$ \\
\hline XIAP & p53 & 0.146 & 0.0931 & $-0.08552-0.2659$ \\
\hline
\end{tabular}

was studied using curves constructed by the Kaplan-Meier method and by the log-rank test. Time of surveillance was counted from the day of diagnosis to the day this study was concluded.

To evaluate the correlations between different markers on patient tumor tissues and on the non-tumorous mucosa samples, the Spearman Rank-Difference Coefficient of Correlation was used for each marker.

The tests used to verify the correlation of immunoexpression of tumor tissue with non-tumorous mucosa was the t-test for continuous variables (cleaved caspase- 3 and $\mathrm{M} 30, \mathrm{P}<0.001)$ or the Mann-Whitney test for categorical variables (remaining markers, $\mathrm{P}<0.0001$ ). All tests were twotailed.

Positive differences in the immunoexpression of the proteins in the distinct histological carcinoma types were tested by Mann-Whitney test. When this test demonstrated $\mathrm{P}<0.05$, Dunn's post-test for multiple comparisons was used on paired values to specify the differences.

The immunoexpression of diverse markers between tumors of different histological grades was analyzed by the MannWhitney test. The software used in the analyses was Prism 4.0 (Graph Pad Software Inc., San Diego, EUA, 2003) and BioEstat 4.0 (Belém, Brasil, 2005). 
Table III. Correlation of the immunoexpression between the markers in the normal mucosa.

\begin{tabular}{|c|c|c|c|c|}
\hline Marker 1 & Marker 2 & P-value & $\mathrm{r}$ & $95 \% \mathrm{CI}$ \\
\hline cIAP-2 & SMAC & $<0.0001$ & 0.5226 & $0.3794-0.6413$ \\
\hline cIAP-1 & Caspase-3 & 0.1173 & 0.1079 & $-0.07574-0.2845$ \\
\hline Survivin & XIAP & 0.0001 & 0.3185 & 0.1469-0.4715 \\
\hline SMAC & Survivin & $<0.0001$ & 0.4077 & $0.2457-0.5475$ \\
\hline cIAP-2 & XIAP & $<0.0001$ & 0.4746 & $0.3235-0.6022$ \\
\hline cIAP-1 & Ki-67 & 0.0023 & 0.2530 & 0.07503-0.4154 \\
\hline SMAC & Ki-67 & 0.0292 & 0.1677 & $-0.01119-0.3363$ \\
\hline cIAP-1 & Survivin & $<0.0001$ & 0.4335 & 0.2722-0.5712 \\
\hline SMAC & Caspase-3 & 0.0003 & 0.2979 & 0.1253-0.4530 \\
\hline Caspase-3 & M30 & $<0.0001$ & 0.3459 & $0.1769-0.4950$ \\
\hline cIAP-1 & cIAP-2 & $<0.0001$ & 0.6149 & 0.4879-0.7164 \\
\hline cIAP-1 & SMAC & $<0.0001$ & 0.4926 & $0.3417-0.6187$ \\
\hline cIAP-2 & Survivin & $<0.0001$ & 0.6811 & $0.5712-0.7671$ \\
\hline Survivin & Caspase-3 & 0.0323 & 0.1652 & $-0.01527-0.3352$ \\
\hline cIAP-2 & Caspase-3 & 0.063 & 0.1365 & $-0.04388-0.3082$ \\
\hline SMAC & M30 & 0.1654 & 0.0870 & $-0.09376-0.2622$ \\
\hline cIAP-1 & p53 & $<0.0001$ & 0.3544 & 0.1848-0.5035 \\
\hline SMAC & p53 & 0.0026 & 0.2455 & $0.07000-0.4063$ \\
\hline cIAP-2 & p53 & 0.1788 & 0.0820 & $-0.09805-0.2568$ \\
\hline M30 & $\mathrm{Ki}-67$ & 0.4300 & 0.0158 & $-0.1640-0.1945$ \\
\hline Survivin & p53 & 0.4804 & 0.0044 & $-0.1757-0.1843$ \\
\hline cIAP-2 & M30 & 0.108 & 0.1106 & $-0.07014-0.2842$ \\
\hline Caspase-3 & Ki-67 & 0.3630 & -0.0314 & $-0.2095-0.1487$ \\
\hline cIAP-1 & XIAP & $<0.0001$ & 0.3988 & $0.2343-0.5411$ \\
\hline cIAP-1 & M30 & 0.2275 & 0.0680 & $-0.1156-0.2471$ \\
\hline Survivin & M30 & 0.0431 & 0.1541 & $-0.02740-0.3257$ \\
\hline SMAC & XIAP & $<0.0001$ & 0.4333 & $0.2761-0.5680$ \\
\hline Ki-67 & p53 & $<0.0001$ & 0.3365 & 0.1680-0.4859 \\
\hline XIAP & Ki-67 & 0.0055 & 0.2240 & 0.04731-0.3871 \\
\hline cIAP-2 & Ki-67 & 0.2231 & 0.0679 & $-0.1120-0.2436$ \\
\hline XIAP & M30 & 0.1646 & 0.0873 & $-0.09349-0.2625$ \\
\hline Survivin & Ki-67 & 0.489 & 0.0025 & $-0.1776-0.1824$ \\
\hline Caspase-3 & p53 & 0.2066 & 0.0732 & $-0.1075-0.2493$ \\
\hline M30 & p53 & 0.3814 & -0.0270 & $-0.2053-0.1530$ \\
\hline XIAP & Caspase-3 & 0.0867 & 0.1215 & $-0.05904-0.2944$ \\
\hline XIAP & p53 & $<0.0001$ & 0.3631 & 0.1973-0.5087 \\
\hline
\end{tabular}

\section{Results}

IAPs and SMAC. The Spearman Coefficient of Correlation between the IAPs, SMAC, Apoptotic Index (AI obtained by cleaved caspase-3 and M30), Ki-67 and p53 for tumor tissue and non-tumorous mucosa are shown in Tables II and III, respectively. The proteins presenting a direct correlation between their immunoexpression are shown in bold.

Fig. 1 shows the immunoexpression of these markers in the tissues studied. In tumor tissue, direct correlation occurred between all four IAPs studied and between these proteins and SMAC (Table II). The same correlations were obtained for non-tumorous mucosa (Table III).
Apoptotic index (AI). XIAP was the only IAP that did not correlate with the tumor tissue AI, obtained by cleaved caspase- 3 and cleaved cytokeratin-18 (M30) immunoexpression. The remaining IAPs (survivin, cIAP-1 and cIAP-2) and their inhibitor SMAC, demonstrated a direct correlation with the AI obtained by both markers (Table II). In contrast, for nontumorous mucosa, only SMAC and survivin showed direct correlation with the AI obtained by cleaved caspase- 3 and only a weak correlation was obtained for survivin using M30 (Table III).

AI evaluation by cleaved caspase- 3 immunoreaction was more clearly defined and greater than that obtained by M30 (Fig. 1). Although there was a direct correlation between 

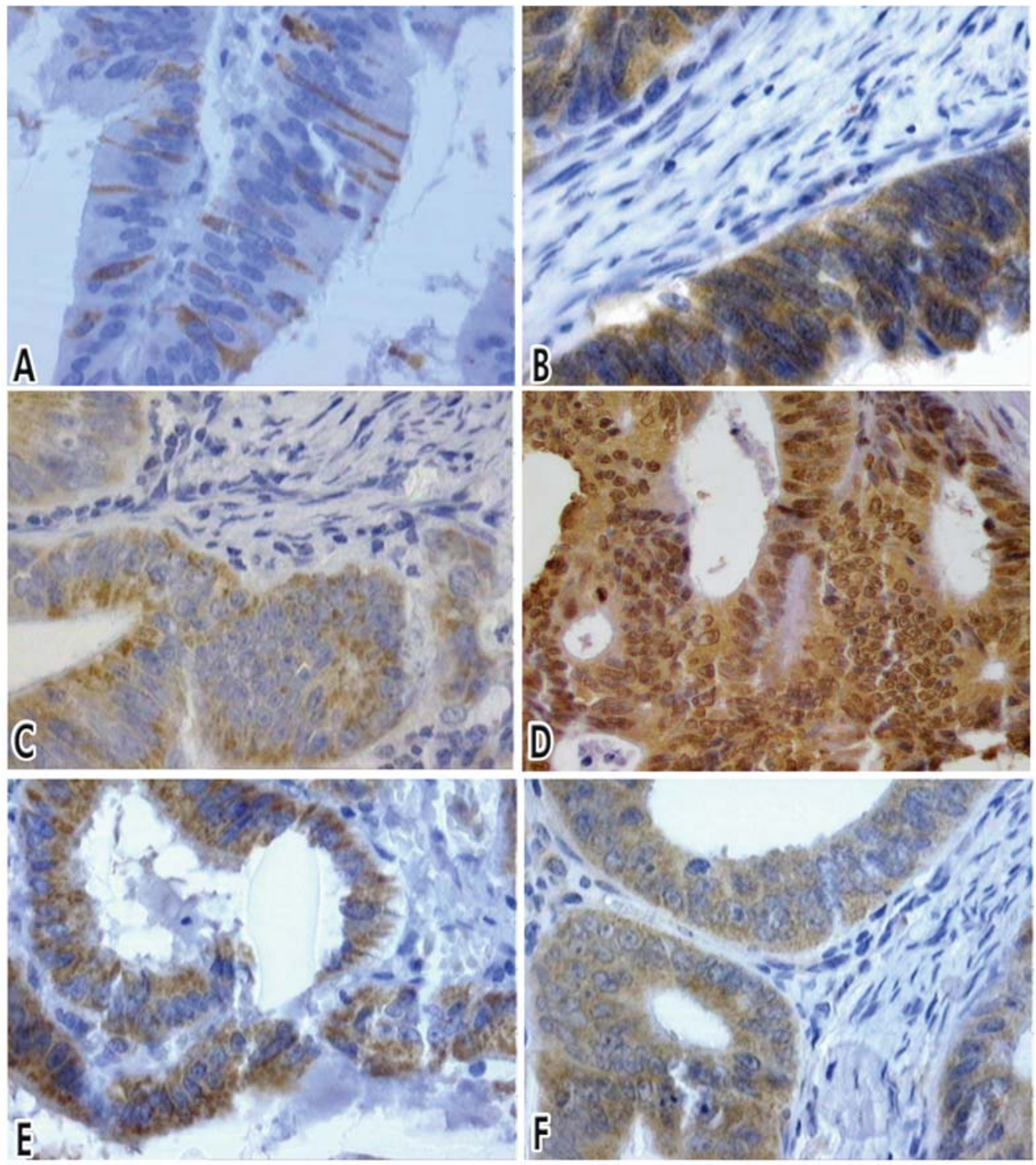

Figure 1. Immunoexpression of cleaved caspase-3, IAPs and SMAC in colorectal cancer tissue: (A) cleaved caspase-3, (B) cIAP-1, (C) cIAP-2, (D) XIAP, (E) survivin and (F) SMAC (x40).

IAPs and SMAC using both AI markers, this was best evaluated when using cleaved caspase-3, particularly for non-tumorous mucosa.

Cellular proliferation (Ki-67) and p53. A direct correlation between Ki-67 immunoexpression and SMAC, cIAP-1 and XIAP was found, but not for survivin or cIAP-2. Similar results were obtained for correlations between $\mathrm{p} 53$ immunoexpression (Table II).

Tumor and non-tumorous mucosa. The differences between the immunoexpression of the IAPs and SMAC in tumor and non-tumorous mucosa tissues were significant for SMAC (mean in tumor tissue $=5.233$; standard deviation $(\mathrm{sd})=2.7$; $\mathrm{m}=2.91$ in the normal mucosa, $\mathrm{sd}=2.3 ; \mathrm{P}<0.0001)$, XIAP $(\mathrm{m}=7.038$ in the tumor tissue, $\mathrm{sd}=1.7 ; \mathrm{m}=5.95$ in the normal mucosa, $\mathrm{sd}=1.8, \mathrm{P}<0.0001)$ and cIAP-1 $(\mathrm{m}=5.764$ in the tumor, $\mathrm{sd}=2.6$ and $\mathrm{m}=4.51$ in the normal mucosa, $\mathrm{sd}=2.3$; $\mathrm{P}=0.0001$ ), with greater expression in tumor tissue. Similar results were found for AI by cleaved caspase- $3(\mathrm{~m}=11.83$ in the tumor, $\mathrm{sd}=10.6$; and $\mathrm{m}=3.32$ in the normal mucosa, $\mathrm{sd}=4.9 ; \mathrm{P}<0.0001), \mathrm{M} 30(\mathrm{~m}=4.446$ in the tumor, $\mathrm{sd}=6.89$, and $\mathrm{m}=1.71$ in the normal mucosa, $\mathrm{sd}=4.34, \mathrm{P}<0.0001)$ and for Ki-67 $(\mathrm{m}=2.908$ in the tumor, $\mathrm{sd}=2.70$, and $\mathrm{m}=0.68$ in the normal mucosa, $\mathrm{sd}=1.48, \mathrm{P}<0.0001)$ and $\mathrm{p} 53(\mathrm{~m}=4.392$ in the tumor, $\mathrm{sd}=3.53$, and $\mathrm{m}=0.23$ in the normal mucosa, $\mathrm{sd}=0.72$, $\mathrm{P}<0.0001)$. No significant differences were observed for survivin and cIAP-2 immunoexpression between tumor and non-tumorous mucosa tissues.

Tumor grade and histological types. Only XIAP immunoexpression was significantly greater in low grade tumors $(\mathrm{m}=7.15, \mathrm{sd}=1.7)$ compared to high grade $(\mathrm{m}=5.38, \mathrm{sd}=1.0$; $\mathrm{P}=0.0131$ ). cIAP-1 revealed greater staining in tubular adenocarcinomas $(m=5.148, \mathrm{sd}=2.6)$ compared to the mucinous carcinomas $(\mathrm{m}=3.429, \mathrm{sd}=3.0 ; \mathrm{P}<0.05)$. XIAP staining was significantly greater in tubular adenocarcinomas $(m=7.94, s d=1.6)$ compared to medullary carcinomas $(\mathrm{m}=5.571, \mathrm{sd}=1.1 ; \mathrm{P}<0.05)$. Survivin revealed greater immunoexpression in tubular adenocarcinomas $(\mathrm{m}=4.000, \mathrm{sd}=2.6)$ 


\section{Survival of IAP-1:Survival proportions}

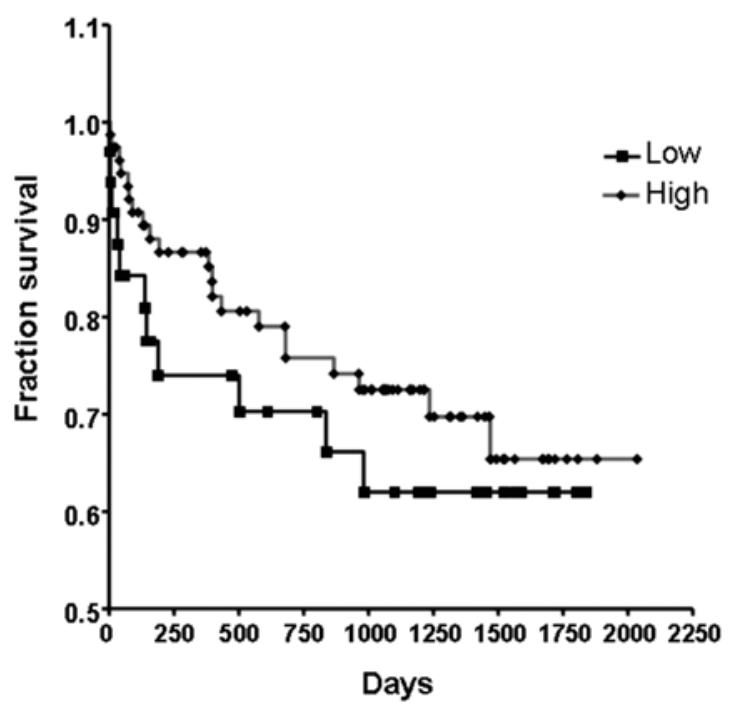

Survival of IAP-1:Survival proportions

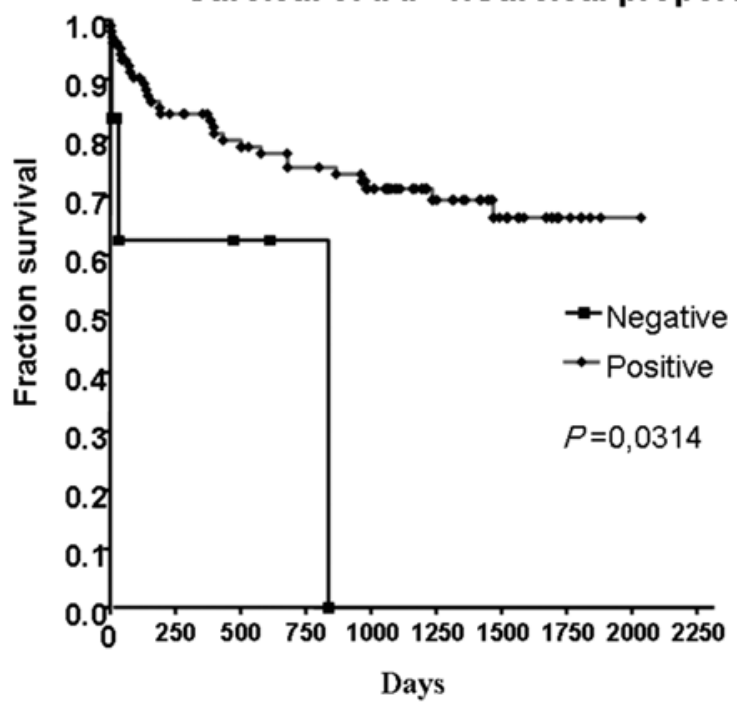

Figure 2. Survival curves comparing the behavior of tumors with low levels versus high levels of expression of IAP-1 (A) or negative versus positive for IAP-1 (B).

compared to mucinous carcinomas $(\mathrm{m}=1.929, \mathrm{sd}=2.5$ $\mathrm{P}<0.01)$.

Survival. Survival data were available for 111 of the 130 patients. Table I shows the cut-off points obtained for the markers studied using histograms. The Kaplan-Meier curves showed no significant differences regarding patient survival between the groups presenting high or low/negative immunoexpression. Only cIAP-1 showed a tendency towards shorter survival in patients presenting low immunoexpression (Fig. 2). Individuals presenting a score of 0 (group negative for cIAP-1, $\mathrm{n}=6$ ) were selected and the resulting curve clearly revealed shorter survival in patients presenting negative for cIAP-1 (Fig. 2).

\section{Discussion}

Apoptosis is the mechanism of cell death that occurs in physiological processes involving growth, embryonic development and homeostatic cell tissue control, as well as the immunological activity of lymphoid tissue (9). Caspases are effector enzymes for the apoptotic process and their activity is subject to rigorous molecular control by inhibitors of apoptosis proteins (IAPs), which in turn are controlled by molecular inhibitors. SMAC/DIABLO is the principal apoptosis inhibitor and the most studied (10-14,26,28). Both IAPs and their inhibitor SMAC are considered potential therapeutic targets concerning the treatment of neoplasias and degenerative neural processes $(18,19,29-31,37,41)$.

The present findings showed a direct correlation between the immunoexpression of all four IAPs studied, both in tumorous and non-tumorous mucosa, and of these proteins with their inhibitor SMAC. Proposed mathematical models predict a dynamic relation between the number of IAP and SMAC molecules present in cells $(27,34,35)$. Therefore an expected and often found inverse relation exists between these proteins in dynamic experiments involving cell cultures, which explains the direct correlations obtained. The current findings indicate that tumors and tissues presenting a high immunoexpression of IAPs also present greater SMAC expression and reveal an impulse towards dynamic homeostatic equilibrium between the quantities of these proteins within the cells.

Concerning the apoptotic index (AI), despite achieving good results with cleaved cytokeratin-18 (M30) for AI evaluation $(40,42,43)$, the present results were more consistent when using cleaved caspase-3.

A direct correlation between AI and SMAC immunoexpression was expected and corroborated evidence regarding the function of this protein as the principal XIAP inhibitor, which liberates caspase- 3 for the apoptotic process. A similar direct correlation of AI with survivin, cIAP-1 and cIAP-2 indicates that the antiapoptotic function of these proteins works by inhibiting SMAC and liberating the blocking action of XIAP against cleaved caspase-3. Other authors have also detected a direct correlation between AI and survivin immunoexpression, with both markers found to be increased in tumor tissue (43). However, an inverse correlation was reported by Rodel et al (44). XIAP was the only protein that did not directly correlate with AI, most likely because it is a direct potent inhibitor of cleaved caspase- 3 and, consequently, of AI. The absence of an inverse correlation between XIAP immunoexpression and AI should be further investigated with a larger series or by using anti-XIAP antibodies against different epitopes of this protein.

The direct correlation found between cellular proliferation, measured by Ki-67 immunoexpression with AI, XIAP, SMAC and cIAP-1 suggest that both apoptosis and cellular proliferation are abnormally increased in colon cancer, as occurs with increased p53, previously reported by Rodel et al (44). 
When comparing tumor tissue and peritumoral nontumorous mucosa, greater values for AI, cellular proliferation and p53 immunoexpression in the tumor tissues validated the present results. Greater XIAP immunoexpression in tumor tissues reinforces the findings of other groups $(45,46)$. Increased tumor immunoexpression for SMAC and cIAP-1 fit the models and experimental findings proposed for dynamic relations between the regulatory proteins of caspase- 3 activation $(27,34,35)$.

Survivin was initially considered absent and unexpressed in normal tissues, as reported by numerous authors (13,47-51). Posterior studies using RT-PCR and immunohistochemistry involving newer antibodies and reagents have revealed the presence of survivin in non-tumorous tissues, especially in colon mucosa adjacent to carcinomas $(21,22,52)$. One of these experiments involved the same reagent used in the present study (52). Survivin positivity has been described both in the nucleus and cytoplasm. Data on the immunohistochemical pattern of cIAP-1 and cIAP-2 are scarce (42).

The rare differences found in the immunoexpression of IAPs and SMAC in relation to tumor histological type and grade reflect the uniformity of the current series. Evidence of a greater XIAP presence in tubular carcinomas than in medullary carcinomas and similar findings for cIAP-1 and survivin in tubular carcinomas than in mucinous carcinomas deserves further investigation with a larger series with those histological types.

The separation of groups into high and low marker immunoexpression is characterized by the variation in criteria between diverse research groups. We chose to construct histograms using the values obtained for each marker to determine a cut-off between the high and low immunoexpression groups. Separating these groups based on the histograms made the determination of the cut-off values more natural and more representative.

The patient survival and mortality data showed that very little time had elapsed from diagnosis up to end of the study period, with half of the patients still alive $(n=56)$. Thus, the lack of correlation between the immunoexpression of the majority of the markers studied (XIAP, SMAC, survivin and cIAP-2) and survival should be analyzed in this context and re-assessed. This fact also heightens the significance of the tendency towards shorter survival among patients presenting low cIAP-1 immunoexpression and the markedly poor survival of those who presented cIAP-1-negative tumors.

Direct correlations between the IAPs and SMAC corroborate the models of apoptosis regulation, which propose a fine balance between the quantities of molecules of these proteins within the cell. SMAC plays an important role in the control of IAP activity and in the sensitization of tumor cells to apoptosis, as shown by the direct correlation with AI. The fact that XIAP was the only IAP for which no direct correlation was observed with AI indicates that XIAP might be a valid therapeutic target and that its inhibition might be used to increase the sensitivity of colorectal cancer to radio and chemotherapy.

The increased values for XIAP, SMAC and cIAP-1 in tumors presenting high indices of cellular proliferation, p53 immunoexpression and AI show that these proteins play an important role in tumorigenesis and evolution.
The presence of survivin in non-tumorous mucosa adjacent to the tumor reinforces previous findings and emphasizes the role of this protein in the non-neoplastic cell population homeostasis. The presence of survivin in the cytoplasm or nucleus could be related to the method used in the investigation, as well as to the metabolic status and cell type studied. The tendency towards shorter survival among patients presenting low cIAP-1 immunoexpression indicates the potential use of this protein as a prognostic marker.

\section{Acknowledgements}

CAPES (Coordenação de Aperfeiçoamento de Pessoal de Nível Superior) scholarship No.330901. FAPESP (Fundação de Amparo à Pesquisa do Estado de São Paulo), 'Apoptose em Tumores' project No.2004/09932-4.

\section{References}

1. Vogelstein B, Fearon ER, Hamilton SR, Kern SE, Preisinger AC, Leppert M, Nakamura Y, White R, Smits AM and Bos JL: Genetic alterations during colorectal-tumor development. N Engl J Med 319: 525-532, 1988 .

2. Fearon ER and Vogelstein B: A genetic model for colorectal tumorigenesis. Cell 61: 759-767, 1990.

3. Arnold CN, Goel A, Blum HE and Boland CR: Molecular pathogenesis of colorectal cancer: implications for molecular diagnosis. Cancer 104: 2035-2047, 2005.

4. Conlin A, Smith G, Carey FA, Wolf CR and Steele RJ: The prognostic significance of K-ras, p53, and APC mutations in colorectal carcinoma. Gut 54: 1283-1286, 2005.

5. Barrier A, Boelle PY, Roser F, Gregg J, Tse C, Brault D, Lacaine F, Houry S, Huguier M, Franc B, Flahault A, Lemoine A and Dudoit S: Stage II colon cancer prognosis prediction by tumor gene expression profiling. J Clin Oncol 24: 4685-4691, 2006.

6. Caldwell GM, Jones CE, Taniere P, Warrack R, Soon Y, Matthews GM and Morton DG: The Wnt antagonist sFRP1 is downregulated in premalignant large bowel adenomas. Br J Cancer 94: 922-927, 2006.

7. Lyall MS, Dundas SR, Curran S and Murray GI: Profiling markers of prognosis in colorectal cancer. Clin Cancer Res 12: 1184-1191, 2006.

8. Penegar S, Wood W, Lubbe S, Chandler I, Broderick P, Papaemmanuil E, Sellic G, Gray R, Peto J and Houlston R: National study of colorectal cancer genetics. Br J Cancer 97: 1305-1309, 2007.

9. Hengartner MO: The biochemistry of apoptosis. Nature 407: 770-776, 2000.

10. Kumar S: Caspase function in programmed cell death. Cell Death Differ 14: 32-43, 2007.

11. Liston P, Fong WG and Korneluk RG: The inhibitors of apoptosis: there is more to life than $\mathrm{Bcl} 2$. Oncogene 22: 8568-8580, 2003.

12. Callus BA and Vaux D: Caspase inhibitors: viral, cellular and chemical. Cell Death Differ 14: 73-78, 2007.

13. Deveraux QL and Reed JC: IAP family proteins - suppressors of apoptosis. Genes Dev 13: 239-252, 1999.

14. Hay BA: Understanding IAP function and regulation: a view from Drosophila. Cell Death Differ 7: 1045-1056, 2000.

15. Bruno T, Iezzi S, De Nicola F, Di Padova M, Desantis A, Scarsella M, Di Certo MG, Leonetti C, Floridi A, Passananti C and Fanciulli M: Che-1 activates XIAP expression in response to DNA damage. Cell Death Differ 15: 515-520, 2008.

16. Rigaud S, Fondaneche MC, Lambert N, Pasquier B, Mateo V, Soulas P, Galicier L, Le Deist F, Rieux-Lacaut F, Revy P, Fischer A, De Saint Basile G and Latour S: XIAP deficiency in humans causes an X-linked lymphoproliferative syndrome. Nature 444: 110-114, 2006.

17. Kim EH, Kim HS, Kim SU, Noh EJ, Lee JS and Choi KS: Sodium butyrate sensitizes human glioma cells to TRAILmediated apoptosis through inhibition of $\mathrm{Cdc} 2$ and the subsequent downregulation of survivin and XIAP. Oncogene 24: 6877-6889, 2005. 
18. Vogler M, Durr K, Jovanovic M, Debatin KM and Fulda S: Regulation of TRAIL-induced apoptosis by XIAP in pancreatic carcinoma cells. Oncogene 26: 248-257, 2007.

19. Schimmer AD, Dalili S, Batey RA and Riedl SJ: Targeting XIAP for the treatment of malignancy. Cell Death Differ 13: 179-188, 2006

20. Bilim V, Yuuki K, Itoi T, Muto A, Kato T, Nagaoka A, Motoyama $\mathrm{T}$ and Tomita Y: Double inhibition of XIAP and $\mathrm{Bcl}-2$ axis is beneficial for retrieving sensitivity of renal cell cancer to apoptosis. Br J Cancer 98: 941-949, 2008

21. Endo T, Abe S, Seidlar HB, Nagaoka S, Takemura T, Utsuyama M, Kitagawa M and Hirokawa K: Expression of IAP family proteins in colon cancers from patients with different age groups. Cancer Immunol Immunother 53: 770-776, 2004.

22. Pinho MDSL, Ghislandi LR, Fronza H Jr, Wengerkiewicz A, Pereira Filho A, Ferreira LC, Kleinubing H Jr and Ferreira LE: Valor prognóstico da expressão da proteína survivina em pacientes submetidos a tratamento cirusgico no cancer coloretal. Rev Bras Coloproct 25: 121-127, 2005.

23. Rodriguez JA, Span SW, Ferreira CG, Kruyt FA and Giaccone G: CRM1-mediated nuclear export determines the cytoplasmic localization of the antiapoptotic protein Survivin. Exp Cell Res 275: 44-53, 2002.

24. Vegran F, Boidot R, Oudin C, Defrain C, Rebucci M and Lizard-Nacol S: Association of p53 gene alterations with the expression of antiapoptotic survivin splice variants in breast cancer. Oncogene 26: 290-297, 2007.

25. Barnes N, Haywood P, Flint P, Knox WF and Bundred NJ: Survivin expression in in situ and invasive breast cancer relates to COX-2 expression and DCIS recurrence. Br J Cancer 94: 253-258, 2006.

26. Altieri DC: Survivin, versatile modulation of cell division and apoptosis in cancer. Oncogene 22: 8581-8589, 2003.

27. Stucki JW and Simon HU: Mathematical modeling of the regulation of caspase-3 activation and degradation. $J$ Theor Biol 234: 123-131, 2005

28. Verhagen AM, Kratina TK, Hawkins CJ, Silke J, Ekert PG and Vaux DL: Identification of mammalian mitochondrial proteins that interact with IAPs via N-terminal IAP binding motifs. Cell Death Differ 14: 348-357, 2007.

29. Wang Q, Wang X and Evers BM: Induction of cIAP-2 in human colon cancer cells through PKC delta/NF-kappa B. J Biol Chem 278: 51091-51099, 2003.

30. Nishihara H, Kizaka-Kondoh S, Insel PA and Eckmann L: Inhibition of apoptosis in normal and transformed intestinal epithelial cells by cAMP through induction of inhibitor of apoptosis protein (IAP)-2. Proc Natl Acad Sci USA 100 8921-8926, 2003

31. Liu Z, Li H, Wu X, Yoo BH, Yan SR, Stadnyk AW, Sasazuki T, Shirasawa S, La Casse EC, Korneluk RJ and Rosen KW: Detachment-induced upregulation of XIAP and cIAP2 delays anoikis of intestinal epithelial cells. Oncogene 25: 7680-7690, 2006.

32. Song Z, Yao X and Wu M: Direct interaction between survivin and Smac/DIABLO is essential for the anti-apoptotic activity of survivin during taxol-induced apoptosis. J Biol Chem 278 : 23130-23140, 2003

33. Ceballos-Cancino G, Espinosa M, Maldonado V and MelendezZajgla J: Regulation of mitochondrial Smac/DIABLO-selective release by survivin. Oncogene 26: 7569-7575, 2007.

34. McNeish IA, Lopes R, Bell SJ, McKay TR, Fernandez M, Lockley M, Wheatley SP and Lemoine NR: Survivin interacts with Smac/DIABLO in ovarian carcinoma cells but is redundant in Smac-mediated apoptosis. Exp Cell Res 302: 69-82, 2005.

35. Rehm M, Huber HJ, Dussmann H and Prehn JH: Systems analysis of effector caspase activation and its control by $\mathrm{X}$ linked inhibitor of apoptosis protein. EMBO J 25: 4338-4349, 2006.
36. Yan H, Thomas J, Liu T, Raj D, London N, Tandeski T, Leachman ST, Lee RM and Grossman D: Induction of melanoma cell apoptosis and inhibition of tumor growth using a cell-permeable Survivin antagonist. Oncogene 25: 6968-6974, 2006.

37. Wang Z, Cuddy M, Samuel T, Welsh K, Schimmer A, Hanaii F, Hougthen R, Pinilla C and Reed JC: Cellular, biochemical, and genetic analysis of mechanism of small molecule IAP inhibitors. J Biol Chem 279: 48168-48176, 2004.

38. Hamilton SR, Rubio CA and Volgelstein B: Tumors of the Digestive System. 1st edition. IARC Press, Lyon, 2000

39. Ogino S, Brahmandam M, Cantor M, Namgyal C, Kawasaki T, Kirkner G, Meyerhardt JA, Loda M and Fuchs CS: Distinct molecular features of colorectal carcinoma with signet ring cell component and colorectal carcinoma with mucinous component. Mod Pathol 19: 59-68, 2006.

40. Holubec H, Payne CM, Bernstein H, Dvorakova K, Bernstein C, Waltmire CN, Warnerke JA and Garewal H: Assessment of apoptosis by immunohistochemical markers compared to cellular morphology in ex vivo-stressed colonic mucosa. J Histochem Cytochem 53: 229-325, 2005.

41. Kim EH, Kim SU and Choi KS: Rottlerin sensitizes glioma cells to TRAIL-induced apoptosis by inhibition of Cdc2 and the subsequent down-regulation of survivin and XIAP. Oncogene 24: 838-849, 2005.

42. Ponnelle T, Chapusot C, Martin L, Bonithon-Kopp C, Bouvier AM, Plenchette S, Rageot D, Faivre J, Solary E and Piard F: Subcellular expression of c-IAP1 and c-IAP2 in colorectal cancers: relationships with clinicopathological features and prognosis. Pathol Res Pract 199: 723-731, 2003

43. Ponnelle T, Chapusot C, Martin L, Bouvier AM, Plenchette S, Faivre J, Solary E and Piard F: Cellular localisation of survivin: impact on the prognosis in colorectal cancer. J Cancer Res Clin Oncol 131: 504-510, 2005

44. Rodel F, Hoffmann J, Grabenbauer GG, Papadopoulos T, Weiss C, Gunther K, Schick C, Sauer R and Rodel C: High survivin expression is associated with reduced apoptosis in rectal cancer and may predict disease-free survival after preoperative radiochemotherapy and surgical resection. Strahlenther Onkol 178: 426-435, 2002.

45. Wu M, Yuan S, Szporn AH, Gan L, Shtilbans V and Burstein DE: Immunocytochemical detection of XIAP in body cavity effusions and washes. Mod Pathol 18: 1618-1622, 2005.

46. Emanuel PO, Phelps RG, Mudgil A, Shafir M and Burstein DE: Immunohistochemical detection of XIAP in melanoma. J Cutan Pathol 35: 292-297, 2008.

47. Sarela AI, Macadam RC, Farmery SM, Markham AF and Guillou PJ: Expression of the antiapoptosis gene, survivin, predicts death from recurrent colorectal carcinoma. Gut 46: 645-650, 2000

48. Kawasaki H, Altieri DC, Lu CD, Toyoda M, Tenjo T and Tanigawa N: Inhibition of apoptosis by survivin predicts shorter survival rates in colorectal cancer. Cancer Res 58: 5071-5074, 1998.

49. Kawasaki H, Toyoda M, Shinohara H, Okuda J, Watanabe I, Yamamoto T, Tanaka K, Tenjo T and Tanigawa N: Expression of survivin correlates with apoptosis, proliferation, and angiogenesis during human colorectal tumorigenesis. Cancer 91: 2026-2032, 2001

50. Abd El-Hameed A: Survivin expression in colorectal adenocarcinoma using tissue microarray. J Egypt Natl Canc Inst 17: 42-50, 2005.

51. Jiang ZM, Yao HR, Zhan J, Xie DR and Li HG: Expression and significance of survivin in colon cancer. Ai Zheng 23: 1414-1417, 2004.

52. Khor TO, Gul YA, Ithnin H and Seow HF: A comparative study of the expression of Wnt-1, WISP-1, survivin and cyclin-D1 in colorectal carcinoma. Int J Colorectal Dis 21: 291-300, 2006. 